\title{
DEGRADABILIDADE RUMINAL DAS SILAGENS DE CAPIM-NAPIER PRODUZIDAS COM DIFERENTES NÍVEIS DE FARELO DE "BATATADIVERSA"
}

\author{
Ruminal degradability of elephant grass produced with different levels \\ of "Discarded Potato" meal
}

\author{
Valério Mendes Rezende ${ }^{1}$ Paulo César de Aguiar Paiva², Adauto Ferreira Barcelos ${ }^{3}$, \\ Júlio César Teixeira ${ }^{4}$, Denismar Alves Nogueira ${ }^{5}$
}

\begin{abstract}
RESUMO
Com o propósito de minimizar os custos com a alimentação, tem-se buscado a utilização dos resíduos viáveis à nutrição animal. "Batata diversa" é o nome atribuído ao tubérculo impróprio para o consumo humano, pois não alcança padrões de comercialização tanto em tamanho quanto em qualidade. A determinação das frações degradáveis ou não no rúmen é de fundamental importância no balanceamento de rações para bovinos. Sendo assim, a técnica de degradabilidade in situ tem sido utilizada para determinar o desaparecimento de nutrientes no rúmen em função do tempo. Dessa forma, objetivou-se produzir e estimar a degradabilidade in situ das diferentes frações da silagem de capim-napier produzida com diferentes níveis do farelo de "batata diversa". O experimento foi conduzido no Departamento de Zootecnia da Universidade Federal de Lavras. Para a ensilagem, foram utilizados silos experimentais de PVC, adaptados com válvula tipo Bünsen, com capacidade para aproximadamente $3 \mathrm{~kg}$ cada. Os tratamentos constituíram-se dos níveis $0 \%, 5 \%, 10 \%, 15 \%$ e $20 \%$ de inclusão do farelo de "batata diversa" ao capim-napier. O delineamento experimental utilizado foi o inteiramente casualizado, com cinco tratamentos e quatro repetições. Este estudo mostrou que a adição de $15 \%$ e $20 \%$ do farelo de "batata diversa" ao ensilar o capim-napier proporcionou melhores resultados que caracterizam uma boa silagem e maiores valores de degradabilidade ruminal in situ da MS, PB e FDN.
\end{abstract}

Termos para indexação: Degradabilidade, silagem, farelo de batata, ruminante.

\begin{abstract}
With the purpose of minimizing the costs of feeding, the use of residues viable to animal nutrition has been searched. "Discarded potato" is the name ascribed to the tuber improper for human consumption, because it does not reach commercialization standards lather in size and quality. The determination of the degradable or not fractions in the rumen is of fundamental importance in the balancing of diets for bovines. So, the in situ degradability technique has been employed to determine the disappearance of nutrients in the rumen as related to the time. Thus, it was aimed to produce and estimate the in situ degradability of the different fractions of elephant grass silage produced with different levels of "discarded potato" meal added to the silage. The experiment was carried out in the Animal Science Department of the Federal University of Lavras. For ensiling, experimental PVC silos fitted with a Bunsen-type valve with a capacity of about $3 \mathrm{~kg}$ each were utilized. The treatments consisted of the levels of $0 \%, 5 \%, 10 \%, 15 \%$ and $20 \%$ of inclusion of "discarded potato" meal into elephant grass. The experimental utilized was the completely randomized design with five treatments and four replicates. This study showed that addition of $15 \%$ and $20 \%$ of "discarded potato" to elephant grass silage provided better results which characterize a good silage and higher values of in situ ruminal degradability for DM, CP and NDF.
\end{abstract}

Index terms: Degradability, silage, potato meal, ruminant.

(Recebido em 23 de março de 2005 e aprovado em 23 de fevereiro de 2005)

\section{INTRODUÇÃO}

A alimentação correta é a base da produção animal e dela depende o êxito financeiro do empreendimento, já que constitui a maior parte do custo de produção no sistema. No propósito de minimizar os gastos com a alimentação, tem-se buscado a utilização de resíduos agroindustriais ou alimentos alternativos viáveis economicamente e nutricionalmente.

Entre estes, o resíduo agrícola da batata, a batata diversa, torna-se uma alternativa viável em função de ser constituída de $57 \%$ de amido na MS e da grande quantidade produzida anualmente. Segundo a Associação Brasileira da Batata (ABBA, 2004), o volume anual que é desperdiçado desse resíduo, em todo Brasil, chega a 100 mil toneladas.

"Batata diversa" é o nome atribuído ao tubérculo impróprio para o consumo humano, por este não alcançar padrões de comercialização tanto em tamanho quanto em qualidade. Porém, pode ser alternativa para a alimentação de ruminantes por apresentar altos teores de amido. Além da qualidade nutricional, a batata diversa tem baixo custo, por ser considerada como resíduo agrícola.

\footnotetext{
Médico Veterinário, MSc. em Nutrição de Ruminantes - valerio.m@bol.com.br

2 Professor do Departamento de Zootecnia da Universidade Federal de Lavras/UFLA - Cx.P. 3037 - 37200-000 - Lavras/MG - pcapaiva@ufla.br

${ }^{3}$ Pesquisador da EPAMIG - CTSM.

${ }^{4}$ Professor do Departamento de Zootecnia da Universidade Federal de Lavras/UFLA UFLA - Cx.P. 3037 - $37200-000$ - Lavras/MG.

${ }^{5}$ Estudante de Doutorado em Estatística Experimental do Departamento de Ciências Exatas da Universidade Federal de Lavras/UFLA
} 
A batata diversa in natura apresenta alto percentual de deterioração em ambientes quentes, tornando difícil a manutenção das suas qualidades bromatológicas por períodos superiores a uma semana, o que dificulta o seu armazenamento e permite classificá-la como perecível. Possivelmente, a melhor maneira de utilizá-la na alimentação animal deverá ser aquela em que se utiliza alguma forma de conservação, seja a desidratação para fazer o farelo, podendo assim ser armazenado por maior tempo ou ensilagem com algum material que necessite de elevação do teor de matéria seca (MS).

O uso do capim-napier na forma de silagem para suplementação de bovinos na época seca do ano tem sido objeto de estudo de pesquisadores nas últimas décadas. Vilela (1990) sugere que a idade de corte ideal para a ensilagem do capim-napier varia de 56 a 80 dias, porém, nessa fase, o baixo teor de MS (20\%) pode comprometer a qualidade da silagem.

O farelo de batata diversa como fonte de aditivo para ensilagem de capim-napier poderá ser alternativa para elevar o teor de MS da silagem, possibilitando fermentações desejáveis dentro do silo.

A determinação de frações degradáveis ou não no rúmen é de fundamental importância no balanceamento de rações para bovinos. Por isso, o uso da técnica de degradabilidade in situ tem sido indicado para determinar o desaparecimento de nutrientes no rúmen em função do tempo.

Objetivou-se, com este trabalho, produzir, determinar a composição bromatológica e estimar a degradabilidade in situ das silagens de capim-napier produzidas com diferentes níveis do farelo de batata diversa.

\section{MATERIAL E MÉTODOS}

O experimento foi realizado no período de novembro de 2003 a outubro de 2004, no Departamento de Zootecnia da Universidade Federal de Lavras, Minas Gerais, Brasil, em parceria com o Centro Tecnológico do Sul de Minas (CTSM), da Empresa de Pesquisa Agropecuária de Minas Gerais (EPAMIG), em Lavras, MG.

A batata diversa utilizada para a obtenção do farelo foi proveniente da beneficiadora de batata do município de Congonhal, Minas Gerais, Brasil.

Inicialmente, realizou-se o corte da batata in natura em fatias, em picadeira forrageira estacionária, sendo, em seguida, seca ao sol até atingir teor de MS entre 10 e $15 \%$ e posteriormente ensacada e armazenada em local seco, ventilado e livre de umidade.
O capim-napier utilizado apresentava dois metros de altura e 130 dias de idade.

A colheita do capim-napier foi realizada por corte manual, sendo este picado em picadeira forrageira estacionária e ensilado por 30 dias.

Para ensilagem, foram utilizados silos de PVC de 10 $\mathrm{cm}$ de diâmetro e $60 \mathrm{~cm}$ de comprimento e providos de válvula (Bünsen) para permitir a saída dos gases produzidos durante a fermentação. Os tratamentos estudados foram: T 0 - (Controle) silagem do capim- napier; T 1 - silagem do capim-napier $+5 \%$ do farelo de batata diversa (FBD); T 2 - silagem do capim-napier + $10 \%$ do FBD; $\mathrm{T} 3$ - silagem do capim-napier + 15\% do FBD e T 4 silagem do capim-napier $+20 \%$ do FBD. A adição do FBD foi realizada com base na matéria natural.

$\mathrm{O}$ ensaio de degradabilidade ruminal in situ foi conduzido, utilizando-se três vacas da raça Jersey, com cânulas ruminais. Os animais receberam dieta basal 15 dias antes dos ensaios para efeito de adaptação, contendo, capim-napier picado (60\% da MS) e concentrado (40\% da MS) constituído de $30 \%$ de farelo de batata diversa, $37 \%$ milho, $27 \%$ farelo de soja, $2 \%$ uréia, $1 \%$ fosfato bicálcio e $3 \%$ complexo mineral-vitamínico.

As amostras das silagens foram moídas em peneira com crivos de $5 \mathrm{~mm}$ e colocadas em sacos de náilon com dimensões de $10,0 \mathrm{~cm}$ de largura por $10,0 \mathrm{~cm}$ de comprimento, com porosidade de 52 micra, fechados a quente em máquina seladora, contendo $20 \mathrm{mg}$ de $\mathrm{MS} / \mathrm{cm}^{2}$.

As análises laboratoriais de proteína bruta (PB) foram realizadas pelo método kjedahl, o teor de nitrogênio amoniacal como porcentagem do nitrogênio total, conforme AOAC (1990); fibra em detergente neutro e $\mathrm{pH}$, segundo a metodologia descrita por Silva (2004) e a determinação da MS foi realizada em estufa a $105^{\circ} \mathrm{C}$.

$\mathrm{O}$ presente trabalho seguiu o delineamento inteiramente casualizado (DIC) com quatro repetições (silos) para os cinco tratamentos (níveis de adição do FBD: 0, 5, 10, 15 e 20\%).

Os dados das degradações das frações de MS, PB e FDN, foram ajustados ao modelo descrito por Orskov \& McDonald (1979): Deg = a + b (1-e ect), sendo "a" a fração solúvel degradada no tempo zero; "b" a fração insolúvel potencialmente degradável; "c" a taxa de degradação da fração insolúvel potencialmente degradável; e, base do logaritmo neperiano e " $t$ " o tempo de incubação. A degradabilidade efetiva (Dge) foi calculada pela fórmula: Dge $=a+[(b * c) /(c+k)]$, sendo "a", "b" e "c" as estimativas obtidas no modelo de Orskov McDonald (Deg); "k" a taxa de passagem, sendo utilizado k = 0,05 conforme descrito por Orskov \& McDonald (1979). 


\section{RESULTADOS E DISCUSSÃO}

\section{Características das silagens}

Observou-se em todos os tratamentos, silagens de odor agradável, coloração amarelada e ausência de fungos.

Os resultados referentes à composição bromatológica das silagens dos diferentes tratamentos estão apresentados na Tabela 1.

\section{Teor de matéria seca (MS) das silagens}

Os teores de MS das silagens de capim-napier foram influenciados $(\mathrm{P}<0,01)$ pela adição do farelo de batata diversa de forma quadrática $\left(\mathrm{R}^{2}=99,57 \%\right)$.

A Figura 1 contém a degradabilidade da MS da silagem de capim-napier adicionada de farelo de batata diversa (FBD) em função do tempo.

Observa-se, na Figura 1, que, com o aumento dos níveis de FBD, houve aumento na MS degradada em função dos tempos de incubação.

Segundo Muck (2001), o teor de MS de silagens de gramíneas, pode variar de $30 \%$ a $50 \%$. Em silagens com teores menores do que $30 \%$, as perdas por efluente e fermentação por clostrídios é significativa e com teores maiores do que $50 \%$ ocorrem danos por calor e deterioração, devido à dificuldade de compactação.

O teor de MS (Tabela 1) evidencia que a porcentagem de MS observada nas silagens encontra-se dentro dos valores limites citados por Muck (2001).

Os valores da degradabilidade efetiva da MS encontrados neste experimento estão na Tabela 2.

Ribeiro Filho (1998), ao avaliar a degradabilidade efetiva do capim-elefante in natura, encontrou $32,75 \%$, sendo superior aos $30,21 \%$ obtidos neste estudo para a silagem de capim- napier quando não foi adicionada do farelo de batata diversa.

A degradabilidade efetiva da MS de $(48,32 \%)$ para a silagem de capim-napier adicionada de $20 \%$ do farelo de batata diversa foi superior à encontrada para a silagem de sorgo (46,0\%), conforme Martins et al. (1999), porém, inferior ao valor obtido pelos mesmos autores para a silagem de milho $(54,8 \%)$.

TABELA 1 - Teores de matéria seca (MS), proteína bruta (PB), fibra em detergente neutro (FDN) na MS, valores de pH e nitrogênio amoniacal $\left(\mathrm{N}-\mathrm{NH}_{3}\right)$, dos tratamentos.

\begin{tabular}{lccccc}
\hline \multicolumn{1}{c}{ Tratamentos } & MS (\%) & PB $(\%)$ & FDN $(\%)$ & pH & $\mathbf{N}_{-\mathbf{N H}}(\boldsymbol{\%})^{*}$ \\
\hline Silagem napier & 33,55 & 6,13 & 73,1 & 3,71 & 2,38 \\
Silagem napier + 5\% FBD & 36,49 & 6,64 & 71,26 & 3,75 & 3,99 \\
Silagem napier + 10\% FBD & 39,7 & 7,66 & 63,01 & 3,87 & 4,85 \\
Silagem napier + 15\% FBD & 41,07 & 7,68 & 59,00 & 3,96 & 5,44 \\
Silagem napier + 20\% FBD & 42,24 & 7,96 & 52,5 & 4,00 & 5,50 \\
\hline
\end{tabular}

$* \mathrm{~N}_{-} \mathrm{NH}_{3}-\%$ do $\mathrm{N}$ total.
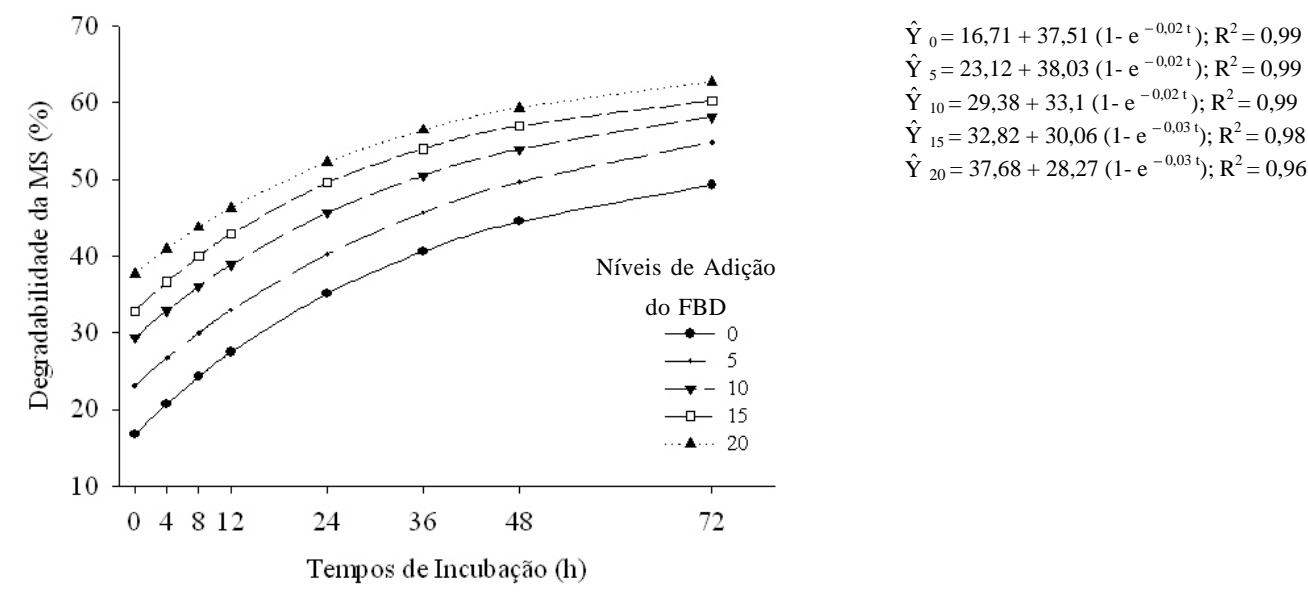

FIGURA 1 - Efeito dos níveis de adição do FBD na degradabilidade da MS da silagem do capim-napier, nos diferentes tempos de incubação (h). 
TABELA 2 - Valores médios de degradabilidade potencial e efetiva da matéria seca (MS) da silagem de capimnapier contendo diferentes níveis de FBD, considerando taxa de passagem $(\mathrm{k})=0,05$.

\begin{tabular}{lcc}
\hline \multirow{2}{*}{ Tratamentos } & \multicolumn{2}{c}{ Degradabilidade (\%) } \\
\cline { 2 - 3 } & Potencial & Efetiva \\
\hline Silagem napier & 54,22 & 30,21 \\
Silagem napier + 5\% FBD & 61,15 & 35,77 \\
Silagem napier + 10\% FBD & 62,48 & 41,31 \\
Silagem napier + 15\% FBD & 62,88 & 44,95 \\
Silagem napier + 20\% FBD & 65,95 & 48,32 \\
\hline
\end{tabular}

\section{Teor de proteína bruta (PB) das silagens}

Os teores de PB das silagens de capim-napier foram influenciados $(\mathrm{P}=0,01)$ pela adição de FBD de maneira linear $\left(\mathrm{R}^{2}=89,06 \%\right)$.

Na Figura 2, apresenta-se a degradabilidade da PB da silagem de capim-napier adicionada de FBD em função do tempo.

Observa-se que, a partir de 48 horas de incubação, houve tendência em estabilizar a degradabilidade da PB nos tratamentos estudados (Figura 2).

Os teores de PB encontrados neste experimento para as silagens com os níveis de 5\%,10\% e 15\% do farelo de batata diversa foram superiores aos encontrados por Balsalobre (1995), quando utilizou os mesmos níveis de inclusão $(5 \%, 10 \%$ e $15 \%)$ de polpa cítrica, adicionada ao capim-napier ensilado em silos laboratoriais por 42 dias, observando valores para PB na MS de 6,4\%, 6,5\% e 6,8\%, respectivamente.

Os valores da degradabilidade efetiva da PB encontrados neste experimento estão apresentados na Tabela 3.

Martins et al. (1999), avaliando a degradabilidade efetiva da PB de silagem de milho e de sorgo, encontraram valores de $70,4 \%$ e $67,9 \%$, respectivamente, os quais foram inferiores ao observado para o nível de inclusão de $20 \%$ para o FBD na ensilagem de capim-napier $(74,88 \%)$.

\section{Teor de fibra em detergente neutro (FDN) das silagens}

Observou-se efeito linear $\left(R^{2}=97,38 \%\right)$ significativo $(\mathrm{P}<0,01)$ nos teores de FDN devido a adição do FBD nas silagens de capim-napier. À medida que aumentaram-se os níveis de FBD de 5\% para 20\%, houve redução de 16,04\% nos teores de FDN das silagens. Essa redução no teor de FDN das silagens com o aumento dos níveis do FBD é explicada pelo fato do teor de FDN na MS do FBD $(13,21 \%)$ ser menor do que o teor de FDN na MS do capim-napier $(76,15 \%)$.
Ferrari Júnior \& Lavezzo (2001), ensilando capimelefante cv. Taiwan A 146, acrescido de farelo de mandioca, nos níveis de $0 \%, 2 \%, 4 \%, 8 \%$ e $12 \%$, obtiveram valores para FDN de $72,91 \%, 68,83 \%, 68,51 \%, 64,99 \%$ e $60,37 \%$ na MS, respectivamente. Como pode ser observado na Tabela 1, quando se adicionou o FBD nos níveis de $15 \%$ e $20 \%$, os teores de FDN foram inferiores aos encontrados por esses autores.

A Figura 3 contém a degradabilidade da FDN da silagem de capim-napier adicionada de FBD em função do tempo.

Observa-se que, com o aumento dos tempos de incubação, as porcentagens de desaparecimento da FDN dos tratamentos em estudo aumentaram efetivamente até as 72 horas (Figura 3).

Os valores da degradabilidade efetiva da FDN encontrados neste experimento estão na Tabela 4.

\section{Valores de pH e nitrogênio amoniacal das silagens}

Houve efeito linear $\left(\mathrm{R}^{2}=89,06 \%\right)$ significativo ( $\mathrm{P}<$ $0,01)$ no $\mathrm{pH}$ e $\mathrm{N}-\mathrm{NH}_{3}\left(\mathrm{R}^{2}=87,80 \%\right)$, para as silagens de capim-napier, quando adicionadas de FBD.

Segundo Rotz \& Muck (1994), um dos princípios básicos da ensilagem é a inibição do desenvolvimento dos microrganismos pelo abaixamento do $\mathrm{pH}$ ou exaustão dos substratos.

Com relação aos parâmetros de avaliação do processo fermentativo, o índice de $\mathrm{pH}$, os ácidos orgânicos e o nitrogênio amoniacal são os mais utilizados. Uma boa silagem deve ter um pH na faixa de 3,8 a 4,2 (LAVEZZO, 1994; RUIZ, 1992).

Os valores de $\mathrm{pH}$ encontrados para os níveis de $10 \%, 15 \%$, e $20 \%$ de inclusão do FBD (Tabela 1), estão em consonância com o recomendado na literatura (LAVEZZO, 1994; RUIZ, 1992) para uma silagem com bom padrão de fermentação. 


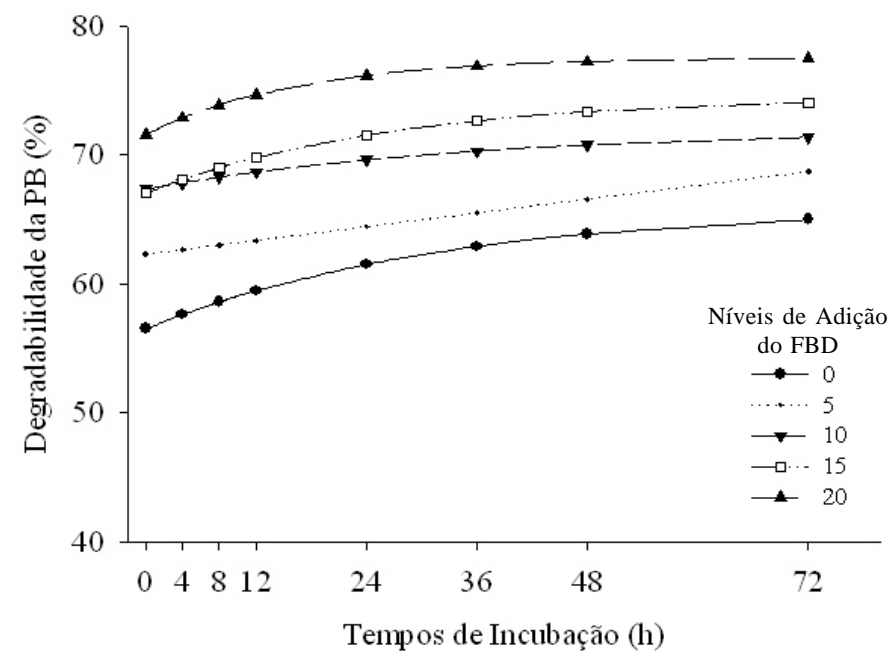

$\hat{\mathrm{Y}}_{0}=56,53+9,45\left(1-\mathrm{e}^{-0,03 \mathrm{t}}\right) ; \mathrm{R}^{2}=0,94$

$\hat{\mathrm{Y}}_{5}=62,31+8,92\left(1-\mathrm{e}^{-0,03 \mathrm{t}}\right) ; \mathrm{R}^{2}=0,91$

$\hat{\mathrm{Y}}_{10}=67,35+4,61\left(1-\mathrm{e}^{-0,02 \mathrm{t}}\right) ; \mathrm{R}^{2}=0,98$

$\hat{Y}_{15}=67,04+7,53\left(1-\mathrm{e}^{-0,03 \mathrm{t}}\right) ; R^{2}=0,94$

$\hat{\mathrm{Y}}_{20}=71,61+5,99\left(1-\mathrm{e}^{-0,06 \mathrm{t}}\right) ; \mathrm{R}^{2}=0,96$

FIGURA 2 - Efeito dos níveis de adição do FBD na degradabilidade da PB da silagem do capim-napier, nos diferentes tempos de incubação $(\mathrm{h})$.

TABELA 3 - Valores médios de degradabilidade potencial e efetiva da proteína bruta (PB) da silagem de capim-napier contendo diferentes níveis de FBD, considerando taxa de passagem $(\mathrm{k})=0,05$.

\begin{tabular}{lcc}
\hline \multicolumn{1}{c}{ Tratamentos } & \multicolumn{2}{c}{ Degradabilidade (\%) } \\
\cline { 2 - 3 } & Potencial & Efetiva \\
\hline Silagem napier & 65,98 & 60,17 \\
Silagem napier + 5\% FBD & 71,23 & 65,66 \\
Silagem napier + 10\% FBD & 71,96 & 69,02 \\
Silagem napier + 15\% FBD & 74,57 & 70,29 \\
Silagem napier + 20\% FBD & 77,60 & 74,88 \\
\hline
\end{tabular}

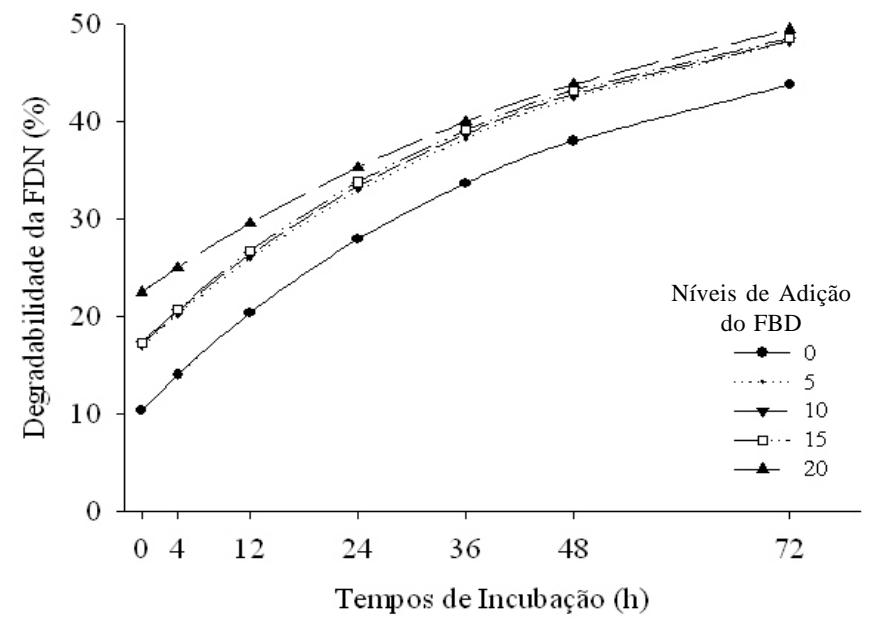

$$
\begin{aligned}
& \hat{\mathrm{Y}}_{0}=10,33+41,10\left(1-\mathrm{e}^{-0,02 \mathrm{t}}\right) ; \mathrm{R}^{2}=0,99 \\
& \hat{\mathrm{Y}}_{5}=16,91+39,93\left(1-\mathrm{e}^{-0,02 \mathrm{t}}\right) ; \mathrm{R}^{2}=0,99 \\
& \hat{\mathrm{Y}}_{10}=17,11+38,78\left(1-\mathrm{e}^{-0,02 \mathrm{t}}\right) ; \mathrm{R}^{2}=0,98 \\
& \hat{\mathrm{Y}}_{15}=17,31+38,36\left(1-\mathrm{e}^{-0,02 \mathrm{t}}\right) ; \mathrm{R}^{2}=0,98 \\
& \hat{\mathrm{Y}}_{20}=22,5+38,28\left(1-\mathrm{e}^{-0,01 \mathrm{t}} \mathrm{t}\right) ; \mathrm{R}^{2}=0,97
\end{aligned}
$$

FIGURA 3 - Efeito dos níveis de adição do FBD na degradabilidade da FDN da silagem de capim-napier, nos diferentes tempos de incubação (h). 
TABELA 4 - Valores médios de degradabilidade potencial e efetiva da fibra em detergente neutro (FDN) da silagem de capim-napier contendo diferentes níveis de FBD, considerando taxa de passagem $(\mathrm{k})=0,05$.

\begin{tabular}{lcc}
\hline \multirow{2}{*}{ Tratamentos } & \multicolumn{2}{c}{ Degradabilidade (\%) } \\
\cline { 2 - 3 } & Potencial & Efetiva \\
\hline Silagem napier & 51,43 & 23,39 \\
Silagem napier + 5\% FBD & 56,84 & 28,81 \\
Silagem napier + 10\% FBD & 55,89 & 29,18 \\
Silagem napier + 15\% FBD & 55,67 & 29,50 \\
Silagem napier + 20\% FBD & 60,78 & 32,19 \\
\hline
\end{tabular}

Em relação ao $\mathrm{N}^{-\mathrm{NH}_{3}}$ (\% N total), Soest (1994) afirma que silagem com baixo teor de nitrogênio amoniacal (inferior a $10 \%$ do nitrogênio total), indica que o processo de fermentação não resultou em quebra excessiva da proteína em amônia. Na Tabela 1, verifica-se que os valores obtidos variaram entre $2,38 \%$ e $5,50 \% \mathrm{~N}$ total, o que indica que não ocorreu degradação excessiva da proteína no decorrer do processo fermentativo.

\section{CONCLUSÕES}

Este estudo mostrou que as adições de $15 \%$ e $20 \%$ de farelo de batata diversa à silagem de capim-napier, proporcionaram melhores resultados que caracterizam uma boa silagem e maiores valores de degradabilidade ruminal in situ da MS, PB e FDN. Portanto, são estes os valores recomendados como aditivo de silagem de capim-napier nas condições estudadas.

\section{REFERÊNCIAS BIBLIOGRÁFICAS}

ASSOCIAÇÃO BRASILEIRA DA BATATA. Desperdício. Batata Show, Itapetininga, v. 4, n. 10, p. 42, nov. 2004.

ASSOCIATION OF OFFICIAL ANALYTICAL CHEMISTS. Official methods of analysis of the Association of Official Analytical Chemists. 15. ed. Washington, 1990. 2 v.

BALSALOBRE, M. A. A. Batata, beterraba, cenoura e nabo. In: SIMPÓSIO SOBRE NUTRIÇÃO DE BOVINOS, 6., 1995, Piracicaba. Anais... Piracicaba: [s.n.], 1995. p. 99-121.

FERRARI JÚNIOR, E.; LAVEZZO, W. Qualidade da silagem de capim-elefante (Pennisetum purpureum Schum.) emurchecido ou acrescido de farelo de mandioca. Revista Brasileira de Zootecnia, Viçosa, v. 30, n. 5, p. 1424-1431, set./out. 2001.
LAVEZZO, W. Ensilagem do capim elefante. In: SIMPÓSIO SOBRE MANEJO DO CAPIM ELEFANTE, 10., 1994, Piracicaba. Anais... Piracicaba: FEALQ/ESALQ, 1994. p. 169-275.

MARTINS, A. de S.; ZEOULA, L. M.; PRADO, I. N. do; MARTINS, E. N.; LOYOLA, V. R. Degradabilidade ruminal in situ da matéria seca e proteína bruta das silagens de milho e sorgo e de alguns alimentos concentrados. Revista Brasileira de Zootecnia, Viçosa, v. 28, n. 5, p. 1109-1117, 1999.

MUCK, R. Conserved forage (silage and hay): progress and priorities. In: INTERNATIONAL GRASSLAND, 19., 2001, São Pedro. Anais... São Pedro: [s.n.], 2001. CDROM.

ØRSKOV, E. R.; McDONALD, I. The estimation of protein degradability in the rumen from incubation measurements weighted according to rate of passage. Journal of Agricultural Science, Cambridge, v. 92, p. 499-503, 1979.

RIBEIRO FILHO, E. Degradabilidade "in situ" da matéria seca (MS), proteína bruta (PB) e fibra em detergente neutro (FDN) da casca de café (Coffea arábica, L.) e desempenho de novilhos mestiços em fase de recria. Lavras: UFLA, 1998. $56 \mathrm{p}$.

ROTZ, C. A.; MUCK, R. E. Changes in forage quality during harvest and storage. In: __ . Forage quality, evaluation and utilization. Madison: ASA/CSSA/SSSA, 1994. p. 828-868.

RUIZ, R. L. Microbiologia zootécnica. São Paulo: Roca, 1992. 314 p. 
SANTOS, R. A. dos. Comparação das técnicas "in situ" e produção de gás na avaliação de alimentos para ruminantes. 2001. 100 p. Tese (Doutorado) - Universidade Federal de Lavras, Lavras, 2001.

SILVA, D. J. Análise de alimentos: métodos químicos e biológicos. 3. ed. Viçosa: UFV, 2004. 235 p.
SOEST, P. J. van. Nutritional ecology of the ruminant. 2. ed. Ithaca: Cornell University, 1994.

VILELA, D. Utilização do capim elefante na forma de forragem conservada. In: SIMPÓSIO SOBRE CAPIM ELEFANTE, 1990, Coronel Pacheco. Anais... Juiz de Fora: Embrapa-Gado de Leite, 1990. p. 89-131. 